\title{
Infection and Foot Care in Diabetics Seeking Treatment in a Tertiary Care Hospital, Bhubaneswar, Odisha State, India
}

\author{
Sonali Kar, ${ }^{1}$ Shalini Ray, ${ }^{2}$ and Dayanidhi Meher $^{3}$ \\ ${ }^{1}$ Department of Community Medicine, Kalinga Institute of Medical Sciences, KIIT University, Patia, Bhubaneswar 751024, India \\ ${ }^{2}$ Kalinga Institute of Medical Sciences, KIIT University, Patia, Bhubaneswar 751024, India \\ ${ }^{3}$ Department of Medicine, Kalinga Institute of Medical Sciences, KIIT University, Patia, Bhubaneswar 751024, India
}

Correspondence should be addressed to Sonali Kar; sonsam72@yahoo.co.uk

Received 10 April 2015; Accepted 21 July 2015

Academic Editor: Gudlavalleti Venkata Murthy

Copyright (C) 2015 Sonali Kar et al. This is an open access article distributed under the Creative Commons Attribution License, which permits unrestricted use, distribution, and reproduction in any medium, provided the original work is properly cited.

\begin{abstract}
Diabetes mellitus is a major public health problem that can cause a number of serious complications. Foot ulceration is one of its most common complications. Poor foot care knowledge and practices are important risk factors for foot problems among diabetics. The present study was undertaken in the diabetes outpatient department of a tertiary care hospital to assess the practices regarding foot care in diabetes, find out the determinants of foot ulcer in diabetics, and offer suggestions to improve care. After informed consent, a total of 124 diabetics were interviewed to collect all relevant information. The diabetic foot care practice responses were converted into scores and for the sake of analysis were inferred as poor (0-5), fair (6-7), and good (>7) practices. Of the study population, $68.5 \%$ (85/124) consisted of men. The disease was diagnosed within the last 5 years for $66 \%$ (81/124) of the study participants. Of the study subjects, 83\% (103/124) were on oral hypoglycemic agents (OHAs), 15.3\% (19) on insulin, and 2 on diet control only. Among them about $18.5 \%$ had a history of foot ulcer. $37.9 \%$ reported using special slippers, $12 \%$ diabetics used slippers indoors, and $66.9 \%$ used slippers while using toilet. Of the study subjects, $67.8 \%$ said that feet should be inspected daily. $27.4 \%$ said they regularly applied oil/moisturizer on their feet. There is a need on part of the primary or secondary physician and an active participation of the patient to receive education about foot care as well as awareness regarding risk factors, recognition, clinical evaluation, and thus prevention of the complications of diabetes.
\end{abstract}

\section{Introduction}

Diabetes mellitus (DM) is a major public health problem depicting a rising prevalence worldwide. Currently, there are an estimated 366 million people affected with diabetes mellitus globally. India is estimated to have 61.3 million diabetics, which is projected to cross 100 million by the year 2030 [1]. Diabetes mellitus is a multifaceted disease and foot ulceration is one of its most common complications. Foot ulcers can cause severe disability and hospitalization to patients and considerable economic burden to families and health systems $[1,2]$. Infection occurring in about half of the diabetic foot ulcers is a further complication. Of all the complications of diabetes, those that occur in the foot are considered the most preventable [3]. Poor knowledge of foot care and poor foot care practices were identified as important risk factors for foot problems in diabetes. Evidence suggests that consistent patient education with prophylactic foot care for those judged to be at high risk may reduce foot ulceration and amputations.

State of Odisha in India has a remarkable prevalence of diabetes with urban prevalence of $15.7 \%$ [4]. The capital of the state, that is, Bhubaneswar, has four tertiary care hospitals, with one being government and the remaining three private. Kalinga Institute of Medical Sciences (KIMS) is a state-ofthe-art private center which harbors a medical college along with facilities for super specialist care. It has an actively functional diabetic clinic with a trained diabetologist. There is a dearth of studies in Odisha, which assessed the diabetic foot care practice of patients, especially in tertiary care setting. With this background the current study was planned in the Diabetes OPD of tertiary care hospital KIMS. 


\section{Methodology}

The study was a hospital based study conducted as a part of a bigger study on skin infections wherein diabetic foot care assessment was undertaken among the attendees of the diabetes OPD of KIMS (conducted in October-December 2014, i.e., one quarter of a year). As specified the assessment aimed at knowing the current foot care practices among the diabetics attending the clinic and through a detailed questionnaire also finds out the determinants of foot ulcer in this population. Ethical clearance was sought from the Institutional Ethics and Research Committee to undertake the study.

The inclusion criteria were set as known cases of type 2 diabetes aged 30 years and above, diagnosed with the disease since at least one-year duration and visiting the diabetic outpatient clinic. Those with cognitive impairment and disability that could affect the functions of the nervous system affect independent self-care behavior, and those who had amputations of the lower limbs [4] and not willing to participate were excluded from the study. All such eligible patients were taken as the study subjects after due informed consent till the desired sample size was achieved. Assuming that $50 \%$ of the diabetics had reasonable knowledge about various factors associated with the disease and that we require a precision of $10 \%$, the sample size is calculated as

$$
N=\frac{4 p q}{d^{2}}=\frac{(4 * 0.5 * 0.5)}{(0.1 * 0.1)}=100 .
$$

Considering $10 \%$ as nonresponse rate, total study subjects interviewed were 124 .

A predesigned pretested semistructured questionnaire certified by the diabetologist at KIMS and translated in local languages like Oriya and Hindi was used, which consisted of sections pertaining to socioeconomic details, awareness regarding diabetes, treatment modalities and compliance, practice of self-care of feet, and feet examination details. Survey instrument regarding diabetic foot care practices was modified and adapted from questionnaire used in previous studies [4-8].

The operational definition of foot ulcer for this study was taken as "a breakdown in the skin below the ankle that may extend to involve the subcutaneous tissue or even to the level of muscle or bone which is non-healing or poorly healing" $[9,10]$.

The diabetic foot care practice responses were converted into scores and for the sake of analysis were inferred as poor (0-5), fair (6-7), and good (>7) practices. Association between poor diabetic foot care practices, knowledge and health seeking behavior, and history of foot ulcer was explored. Patients were asked if they were ever counseled by doctor regarding footcare and use of educational charts for the same by the health provider was also explored. Data was collated and subsequently analyzed using Epi info 7.

\section{Results}

Table 1 depicts the mean age of the study participants was $60.6 \pm 9.13$ years, with nearly $58 \%$ of them having a higher secondary level education and above. Of the study population, $68.5 \%$ consisted of male participants, hinting at a male
TABLE 1: Sociodemographic profile of the respondent diabetics $(n=$ 124).

\begin{tabular}{lcc}
\hline Parameters & Number & $\begin{array}{c}\text { Percentage/mean } \pm \\
\text { sd }\end{array}$ \\
\hline Age in years & 124 & $60.6 \pm 9.13$ \\
Gender & & \\
Male & 85 & 68.5 \\
Female & 39 & 31.4 \\
Education & & \\
Illiterate & 07 & 5.6 \\
Primary & 43 & 34.6 \\
Secondary & 2 & 1.6 \\
Higher secondary & 54 & 43.5 \\
$\quad$ Graduate and above & 18 & 14.5 \\
Occupation & & \\
Unemployed & 2 & 1.6 \\
Unskilled & 13 & 10.4 \\
Semiskilled and skilled & 35 & 28.2 \\
Clerical, shop owner, and farmer & 12 & 9.6 \\
Semiprofessional & 12 & 9.6 \\
& & 17.7 \\
Housewife & 22 & $(56.4 \%$ of female \\
Retired & & subjects $)$ \\
\hline
\end{tabular}

TABLE 2: Details of disease and treatment among study subjects.

\begin{tabular}{lccc}
\hline $\begin{array}{l}\text { Demographic } \\
\text { details }\end{array}$ & Categories & Number $(n=124)$ & Percentage \\
\hline $\begin{array}{l}\text { Duration of } \\
\text { illness (diabetes) }\end{array}$ & $<5$ years & 82 & 66.1 \\
\hline Age at diagnosis & $<50$ years & 42 & 33.8 \\
& $>50$ years & 40 & 67.7 \\
\hline \multirow{2}{*}{ Treatment } & Diet control & 2 & 32.2 \\
\hline Treatment & Drugs & 103 & 1.6 \\
regularity & Insulin & 19 & 83 \\
\hline Foot ulcer & Regular & 90 & 15.3 \\
(past/present) & Irregular & 34 & 72.5 \\
\hline Physical & Yes & 23 & 27.4 \\
activity/exercise & No & 101 & 18.5 \\
\hline
\end{tabular}

predominance of the disease, though the underreporting among females or hesitance to seek health care on their behalf cannot be ruled out. Of the study participants, $5.6 \%$ had not received any formal education. Housewives accounted for $56.4 \%(22 / 39)$ of the female study participants, unskilled workers $10.4 \%$, and farmers, shop owners, and clerical job holders $9.6 \%$ of study participants.

Table 2 shows that the disease was diagnosed within the last five years for $66 \%$ of study population. Of the study 
TABLE 3: Possible determinants of foot ulcer in diabetics.

\begin{tabular}{|c|c|c|c|}
\hline Determinants of foot care in diabetics & Hx of foot ulcer/current ulcer & No foot ulcer & Odds ratio $(95 \% \mathrm{CI})$ \\
\hline \multicolumn{4}{|l|}{ Duration of diabetes } \\
\hline$<5$ years & 12 & 70 & $0.48(0.19-1.21)$ \\
\hline$>5$ years & 11 & 31 & \\
\hline \multicolumn{4}{|l|}{ Treatment compliance } \\
\hline Yes & 8 & 82 & $0.12^{*}(0.04-0.33)$ \\
\hline No & 15 & 19 & \\
\hline \multicolumn{4}{|l|}{ Foot care practice } \\
\hline Poor $(0-5)$ & 19 & 58 & \\
\hline Fair and above (6-10) & 04 & 43 & $3.52^{*}(1.11-11.1)$ \\
\hline \multicolumn{4}{|l|}{ Counseling on foot care } \\
\hline Received & 9 & 76 & $0.21^{*}(0.08-0.54)$ \\
\hline Not received & 14 & 25 & \\
\hline
\end{tabular}

* Significant odds ratio.

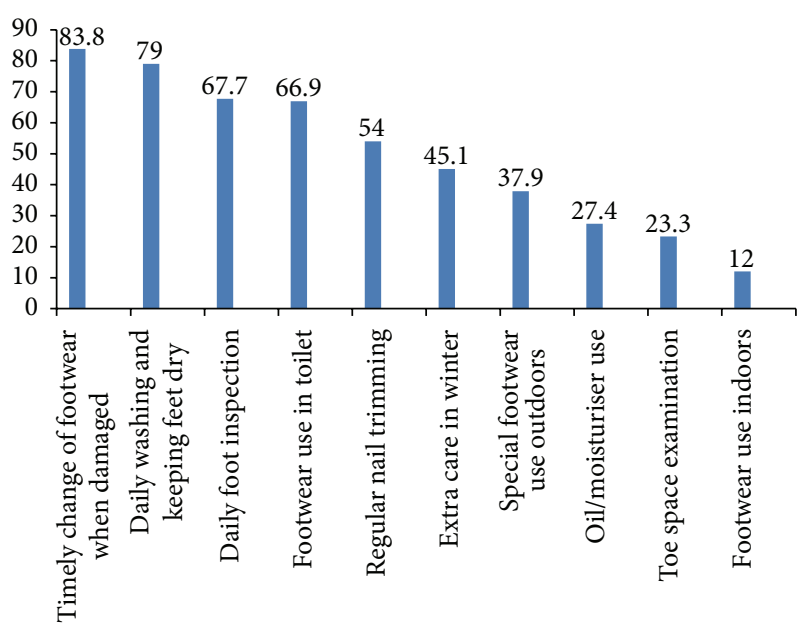

FIGURE 1: Foot care practices among study subjects.

subjects, $83 \%(103 / 124)$ were on oral hypoglycemic agents (OHAs), $15.3 \%$ (19) were on insulin, only $41.9 \%$ of the study subjects were involved in regular exercise or physical activity, and $72.5 \%$ of the diabetics were having good treatment compliance. Among the study subjects $18.5 \%$ (23/124) had a history/current foot ulcer.

Figure 1 shows that, out of the total study population, only $37.9 \%$ reported using special slippers (extra cushioned, thick soled) outdoors, and only $12 \%$ diabetics used footwear indoors though $66.9 \%$ used slippers while using toilet. Of the study subjects, $67.7 \%$ said that feet should be inspected daily. $27.4 \%$ said they regularly applied oil/moisturizer on their feet. Among them, 83.8\% reported change of footwear when damaged or ill-fitted and $45.1 \%$ reported taking extra care in winter. $54 \%$ and $23.3 \%$ of subjects reported regular nail trimming and toe space examination regularly, respectively. However $79 \%$ of the subjects reported daily washing and drying of feet.
After cumulative scoring, $61.6 \%, 32 \%$, and only $5.6 \%$ of the patients had a poor, fair, and good diabetic foot care practice.

Table 3 shows that poor foot care practice (OR 3.52, 95\% CI 1.11-11.1), treatment noncompliance (OR 0.12, 95\% CI 0.04-0.33), and absence of counseling regarding foot care (OR 0.21 , 95\% CI $0.08-0.54$ ) in diabetes were significantly associated with occurrence of foot ulcer in diabetics.

\section{Discussion and Conclusion}

The important findings of the study are that the majority of the participants were males (68.5\%). This could be attributed to the fact that perhaps males have a comparatively better health seeking behavior as compared to females. Nearly $58 \%$ participants were with higher secondary level education and above and this could be explained as the study was undertaken in a tertiary care centre in a city. Nearly $18.5 \%$ of the study subjects reported having foot ulcer. $67.7 \%$ reported daily foot inspection and $37.9 \%$ reported using special slippers outdoors. However, only $12 \%$ of the participants used slippers indoors which could be because of cultural practices. The deficiency in foot care practices in the present study is comparable to similar studies in India and other developing countries where daily inspection of the feet is reported by less than $70 \%$ and special care in winters is taken by less than $50 \%$ of patients [4-6]. In our study, absence of counseling and poor foot care practices were significant determinants of presence of foot ulcer

Regular blood glucose monitoring and compliance to diet and life-style advice were found to be comparatively better in the present study. This is in line with an earlier finding that foot care and health education were least suggested by doctors [11]. This suggests a tip of the iceberg as the study is being undertaken in a city based tertiary care center and now India has become the largest diabetic load country in the world where nearly $70 \%$ of the population are from the rural background. 
Findings can be used to guide a health education program on foot care for diabetics. Emphasis should be laid on such deficient areas by health education and misconceptions should be cleared. This study has few limitations. This is a hospital based study, the results of which do not reflect the awareness and practices in the community. There is a need on part of the doctor and an active participation of the patient to receive education about foot care as well as awareness regarding risk factor recognition, clinical evaluation, and prevention of complications of diabetes.

\section{Conflict of Interests}

The authors declare that there is no conflict of interests regarding the publication of this paper.

\section{References}

[1] World Health Organization, Diabetes Fact Sheet N0312, World Health Organization, Geneva, Switzerland, 2009.

[2] F. Crawford, M. Inkster, J. Kleijnen, and T. Fahey, "Predicting foot ulcers in patients with diabetes: a systematic review and meta-analysis," QJM, vol. 100, no. 2, pp. 65-86, 2007.

[3] V. Viswanathan, R. Shobhana, C. Snehalatha, R. Seena, and A. Ramachandran, "Need for education on footcare in diabetic patients in India," Journal of Association of Physicians of India, vol. 47, no. 11, pp. 1083-1085, 1999.

[4] G. Hanu, P. S. Rakesh, K. Manjunath et al., "Foot care knowledge and practices and the prevalence of peripheral neuropathy among people with diabetes attending a secondary care rural hospital in southern India," Journal of Family Medicine and Primary Care, vol. 2, no. 1, pp. 27-32, 2013.

[5] S. Hasnain and N. H. Sheikh, "Knowledge and practices regarding foot care in diabetic patients visiting diabetic clinic in Jinnah Hospital, Lahore," Journal of the Pakistan Medical Association, vol. 59, no. 10, pp. 687-690, 2009.

[6] S. Saurabh, S. Sarkar, K. Selvaraj, S. Kar, S. Kumar, and G. Roy, "Effectiveness of foot care education among people with type 2 diabetes in rural Puducherry, India," Indian Journal of Endocrinology and Metabolism, vol. 18, no. 1, pp. 106-110, 2014.

[7] N. Unwin, D. Whiting, L. Guariguata, G. Ghyoot, and D. Gan, Eds., Diabetes Atlas, International Diabetes Federation, Brussels, Belgium, 5th edition, 2011.

[8] American Diabetes Association, "Economic costs of diabetes in the U.S. in 2012," Diabetes Care, vol. 36, pp. 1033-1046, 2013.

[9] B. R. Mehra, A. P. Thawait, S. S. Karandikar, D. O. Gupta, and R. R. Narang, "Evaluation of foot problems among diabetics in rural population," Indian Journal of Surgery, vol. 70, no. 4, pp. 175-180, 2008.

[10] http://www.hopkinsguides.com/hopkins/view/Johns_Hopkins_ Diabetes_Guide/547054/all/Foot_Ulcers.

[11] V. N. Shah, P. K. Kamdar, and N. Shah, "Assessing the knowledge, attitudes and practice of type 2 diabetes among patients of saurashtra region, Gujarat," International Journal of Diabetes in Developing Countries, vol. 29, no. 3, pp. 118-122, 2009. 


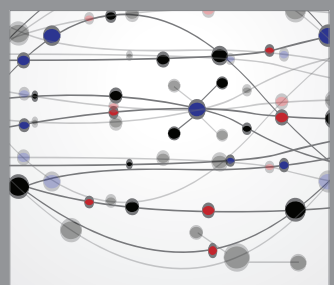

The Scientific World Journal
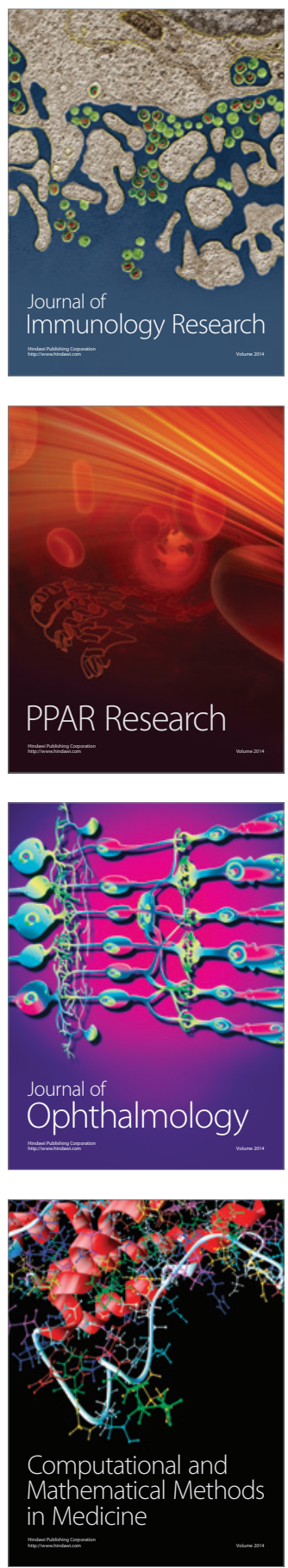

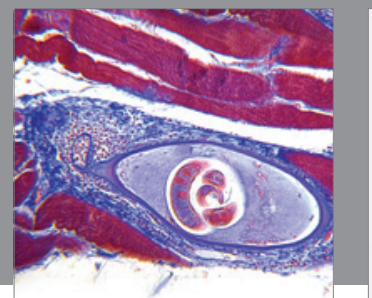

Gastroenterology

Research and Practice
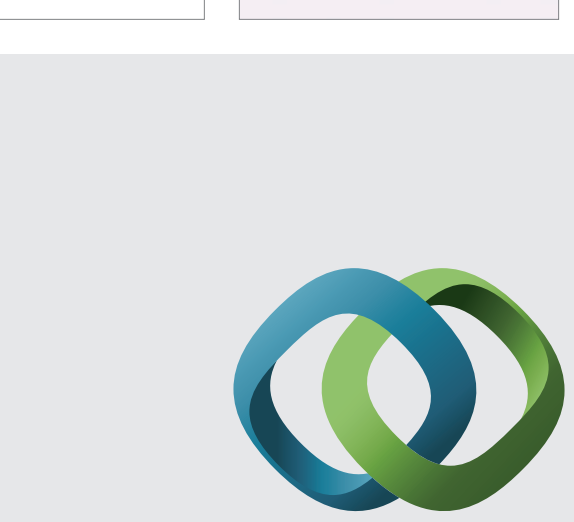

\section{Hindawi}

Submit your manuscripts at

http://www.hindawi.com
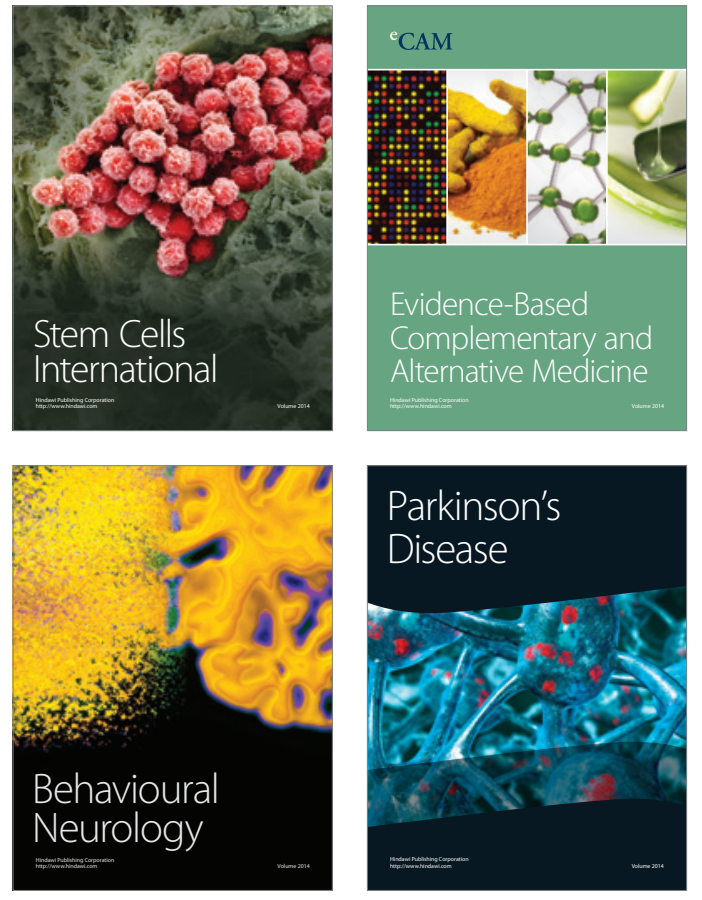
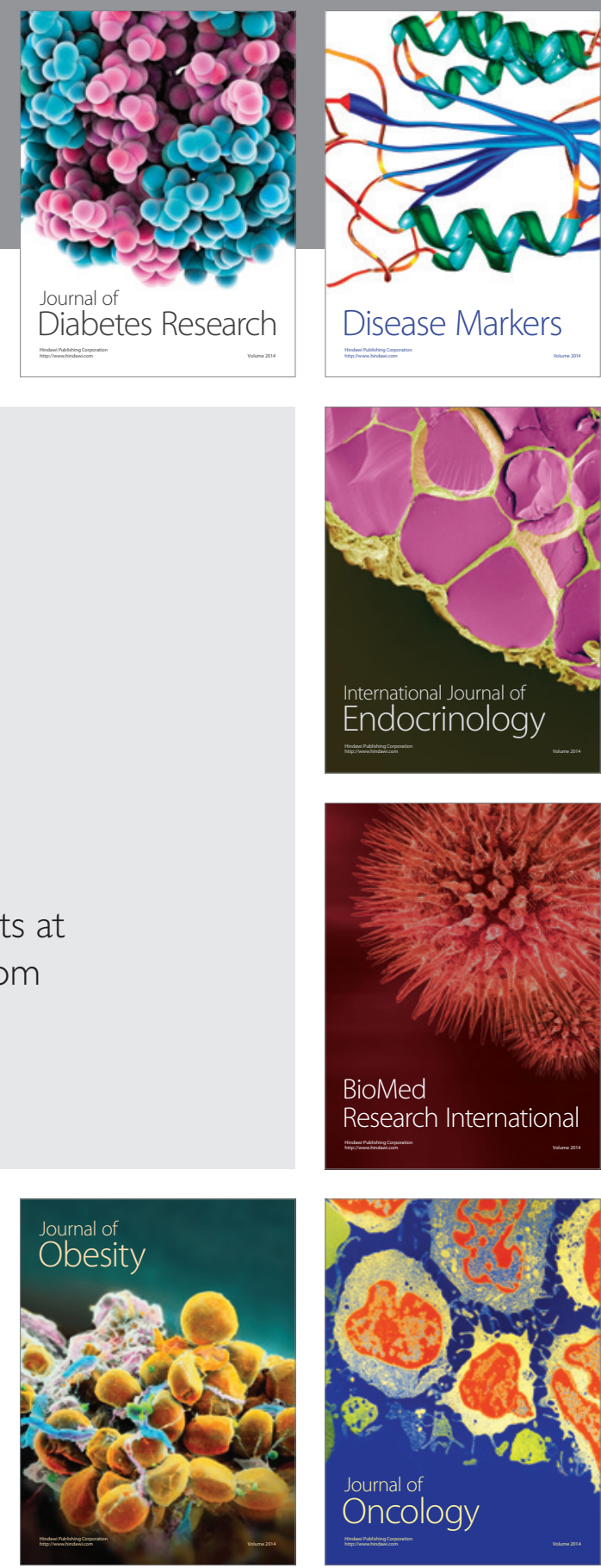

Disease Markers
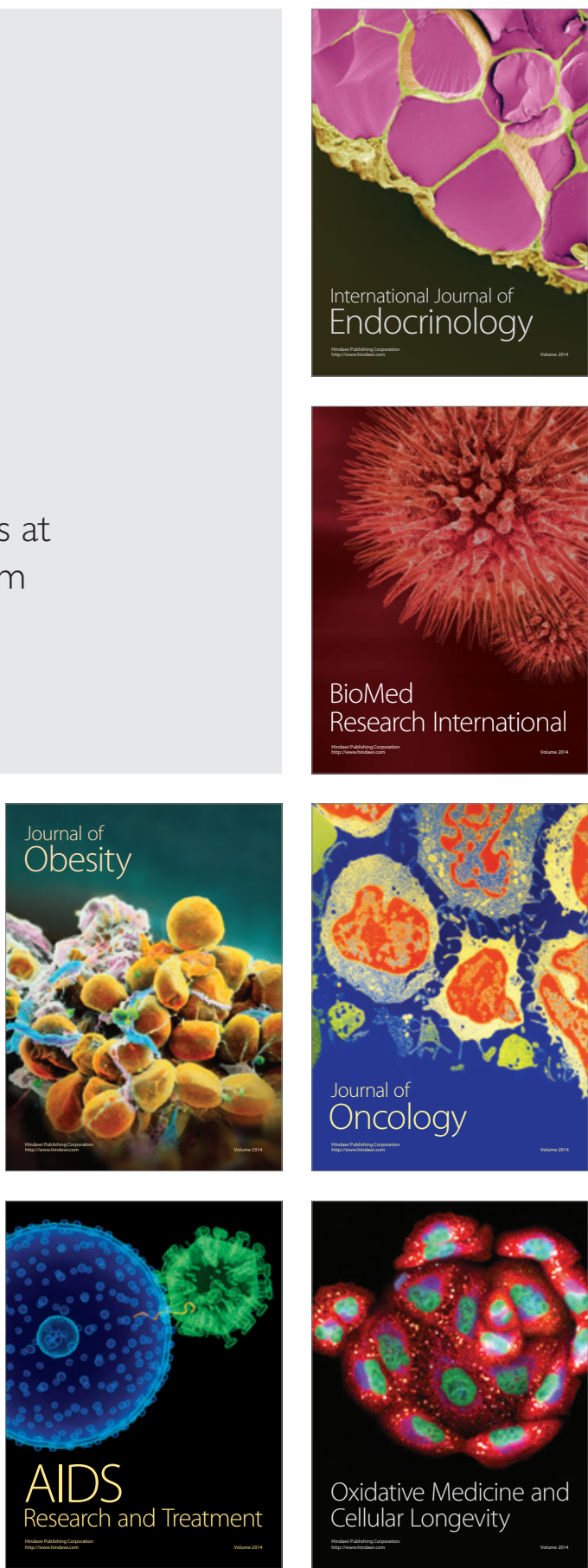